\title{
Possibility of Implement Strategies of Green Buildings in Building Constructions at Kingdom of Saudi Arabia to Achieve Sustainable Development
}

\author{
Ali Nasser Alzaed ${ }^{1}$, Wael W. Al-Buzz ${ }^{2}$

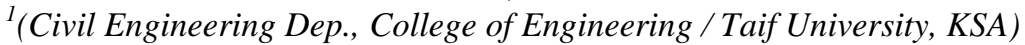 \\ ${ }^{2}$ (Civil Engineering Dep., College of Engineering / Taif University, KSA)
}

\begin{abstract}
The aim of this research is to spot light on the strategy of application of green building systems in the building constructions at Kingdom of Saudi Arabia to Achieve sustainable development, in order to conserve of energy consumption to increase the control and upgrade of thermal efficiency of buildings. Since the summer season of Saudi Arabia is very long, and the sun shines for long time, it is possible to use and application of solar cell systems for generating clean electrical energy, where it is possible to use such electrical energy in irrigation of special plants used as components for the systems of green buildings, consumption of energy will be less, environmental will become more healthy, the efficient of buildings will be better too, because of using such alternatives. First promote the phenomenon of Agriculture inside the houses and around. The advantages of building such system, means that the natural ventilation inside houses increase reducing building energy consumption and improving the indoor environment conditions have become more convenient. Compared with mechanical ventilation or air-conditioning system, there is more potential in the natural ventilation method providing better indoor air quality, while maintaining a healthy and comfortable indoor thermal environment, in addition to reduce pollution, and to save energy for the future generation, and will also increase the aesthetic aspect of buildings.
\end{abstract}

Keywords: Environment, Green Building, Natural Ventilation, Pollution, Sustainability

\section{Introduction}

Saudi Arabia is blessed with an abundance of different energy, foremost of which is the sun, which is alternative energy petroleum, which are called clean energy. The summer of Saudi Arabia is too long, and the sun shines for long time, from which to generate electricity that can be used in different sectors, notably the construction sector or the so-called green buildings, as well as contributing to the preservation of the national inventory of petroleum, which is the right of new generations. Saudi Arabia has "Council of Scientific Society of Green Buildings", non-profit society, founded in 2007 on the initiative of a group of academics and engineers and those interested in the field of environmental construction and science knowledge. It holds an accreditation World Green Building Council, prepared and participated in many workshops and events, local and international conferences for the manufacture of green buildings. Aims to create human consciousness and the preservation of heritage and urban environmental knowledge and support and employment practices optimized for highefficiency construction in Saudi Arabia, The green building movement focuses on reducing the overall environmental impact of new and existing buildings through various methods, such as the use of recycled materials, energy efficient design, and water protection and conservation Most of buildings and Villas in Kingdom of Saudi Arabia seems very huge and very beautiful architectural design. But most of these buildings lack the highlight to plants, which adds a beautiful and elegant view for buildings, which will work to soften the atmosphere, and will also work to reduce the costs of energy consumption. of course there are ways exist even in Saudi Arabia for alternative energy generation and clean that it can be used to irrigate plants, which also means that the use of these plants to protect buildings from the sun warm temperatures. It also helps reduce energy consumption inside houses, and reduce the cost in the electrical bill, and maintain a clean and comfortable environment. The malpractice of the current constructional mode will increase in the energy consumption. While the Taif like other governorates of the Kingdom have a strong interest in the theme parks and the streets are coordinated through the presence of specialists on the subject of landscaping, which calls for attention of the citizens, for the value of these plants aesthetically as well as the physical benefit. This confirms the possibility of growing some plants in home gardens, as well as using different types of plants contribute to the preservation of buildings, by reduced degrees of heat, which means reducing energy consumption also. Then we will find that green buildings are financial feasibility and in many times better than conventional buildings. Therefore, governments should grant preferential to the enterprises that produce green buildings to stimulate the development of green buildings, and encourage people to use such building system, through using different types of media. As well as create sufficient awareness among citizens extent of the importance of using this type of building systems. Green buildings are commonly perceived to be a lot more expensive than conventional buildings and often not worth the extra cost, and now green construction is gaining increasing attention in the 
global context. With the recognition to the concept of sustainable development around the world. So the term of "green buildings" or "green construction" refer to buildings and projects designed with a special focus on efficiency and sustainability. As this movement has begun to gain momentum, various bodies have emerged to promote, substantiate, and verify the legitimacy and benefits of green construction. In this case, after applying all conditions of green building system particular and will avoid antitrust liability for their Leadership in Energy and Environmental Design (LEED).

\section{Green Buildings Concepts}

While buildings and development provide countless benefits to society, they also have significant environmental and health impacts. Green building is the practice of creating structures and using processes that are environmentally responsible and resource-efficient throughout a building's life-cycle from siting to design, construction, operation, maintenance, renovation and deconstruction. This practice expands and complements the classical building design concerns of economy, utility, durability, and comfort. Green building is also known as a sustainable or high performance building. The buildings in which we live, work, and play protect us from nature's extremes, yet they also affect our health and environment in countless ways. As the environmental impact of buildings becomes more apparent, a new field called "green building" is gaining momentum.

Green, or sustainable, building is the practice of creating and using healthier and more resourceefficient models of construction, renovation, operation, maintenance and demolition, fig. 1 show the impacts of the built environment.

\begin{tabular}{|ll|ll|ll|ll|}
\hline \multicolumn{2}{|c|}{ Aspects of Built Environment } & \multicolumn{2}{|c|}{ Consumption } & \multicolumn{2}{c|}{ Environmental Effects } & \multicolumn{1}{c|}{ Ultimate Effects } \\
\hline$\bullet$ & Siting & $\bullet$ & Energy & $\bullet$ & Waste & $\bullet$ & Harm to Human Health \\
$\bullet$ & Design & $\bullet$ & Water & $\bullet$ & Air pollution & $\bullet$ & Environment Degradation \\
$\bullet$ & Construction & $\bullet$ & Materials & $\bullet$ & Water pollution & $\bullet$ & Loss of Resources \\
$\bullet$ & Operation & $\bullet$ & Natural & $\bullet$ & Indoor pollution & \\
$\bullet$ & Maintenance & Resources & $\bullet$ & Heat islands & \\
$\bullet$ & & & $\bullet$ & Storm water runoff & \\
\hline & Deconstruction & & $\bullet$ & Noise & \\
\hline
\end{tabular}

Fig. 1 Impacts of the built environment

So green buildings are designed to reduce the overall impact of the built environment on human health and the natural environment, so the main concept of the green building is, any structure is designed, built, renovated, operated or reused with objectives to protect occupants' health, improve employees' productivity, use natural resources wisely and reduce the environmental impact.

Analogous with industrial ecology which is the starting point for applying ecological principles to human systems

1- Efficiently using energy, water, and other resources.

2- Protecting occupant health and improving employee productivity.

3- Reducing waste, pollution and environmental degradation.

For example, green buildings may incorporate sustainable materials in their construction such as, reused, recycled - content, or made from renewable resources, and create healthy indoor environments with minimal pollutants when reduced product emissions or feature landscaping that reduces water usage by using native plants that survive without extra watering.

\section{The Uses Of Green Buildings}

The built environment has a vast impact on the natural environment, human health, and the economy. By adopting green building strategies, we can maximize both economic and environmental performance. Green construction methods can be integrated into buildings at any stage, from design and construction, to renovation and deconstruction. However, the most significant benefits can be obtained if the design and construction team takes an integrated approach from the earliest stages of a building projects. Potential benefits of green buildings can include:

\subsection{Environmental benefits}

- Enhance and protect biodiversity and ecosystems.

- Improve air and water quality.

- $\quad$ Reduce waste streams.

- Conserve and restore natural resources. 


\subsection{Economic benefits}

- Reduce operating costs.

- Create, expand, and shape markets for green product and services.

- Improve occupant productivity.

- Optimize life-cycle economic performance.

\subsection{Social benefits}

- Enhance occupant comfort and health.

- Heighten aesthetic qualities.

- Minimize strain on local infrastructure.

- Improve overall quality of life.

Buildings also have a significant impact on human health. Indoor air typically contains between 2 and 5, and occasionally greater than 100 - times more pollutants than outdoor air. As a result, poor indoor air quality in buildings has been linked to significant health problems such as cancers, asthma, Legionnaires' disease and hypersensitivity pneumonitis.

The built environment, including buildings and other development, plays a substantial role in environmental health, human welfare and economic stability. The global $\mathrm{CO}_{2}$ Emission per sectors, fig. 2 show the impact of US buildings on resources as shown in the following table.

\begin{tabular}{|c|c|c|c|}
\hline Primary energy use & Electricity consumption & CO2 Emission & Potable water consumption \\
\hline $\mathbf{4 0 \%}$ & $\mathbf{7 2 \%}$ & $\mathbf{3 9 \%}$ & $\mathbf{1 3 . 6 \%}$ \\
\hline
\end{tabular}

Fig. 2 Show the impact of US buildings on resources

Both, the causes and effects of poor Indoor Environmental Quality (IEQ). Major subtopics under indoor environmental quality, include Indoor Air Quality (IAQ) should be study well. Day lighting and ventilation both has an effect on thermal comfort, both of them were often overlap with energy efficiency.

Based on to the vision and mission of the Saudi Green Buildings Council, and its promotion, Saudi Green Buildings Council promotes and facilitates the practice of green building in Saudi Arabia to achieve its vision and mission through the following implementations:

$>$ Raise public awareness, and to provide training and education programs.

$>$ Assist the construction sector to shift towards green buildings.

$>$ Encourage the industrial sectors of building materials industry, and suppliers to produce and supply products that have responsible environmentally.

$>$ Promote and encourage the green evaluation systems.

Taking in account the harmonization and the development and operation of Green Building Rating System (GBRS), which suit local environmental requirements, taking into account international experience. So green building can be defined very broadly, as a large number of factors contribute to human and ecological health as they relate to the built environment.

\section{Study Case}

The US federal government is spending huge amounts of money for research and development process to the subject of green buildings, and to encourage citizens to use this style of construction. Between 2002 and 2004, federal green building research accounted for approximately $0.2 \%$ of all federally funded research $-\mathrm{a}$ percentage that appears disproportionate to the benefits that can be gained by improving the efficiency and the health and environmental quality of buildings. As shown in the following diagram fig. 3 .

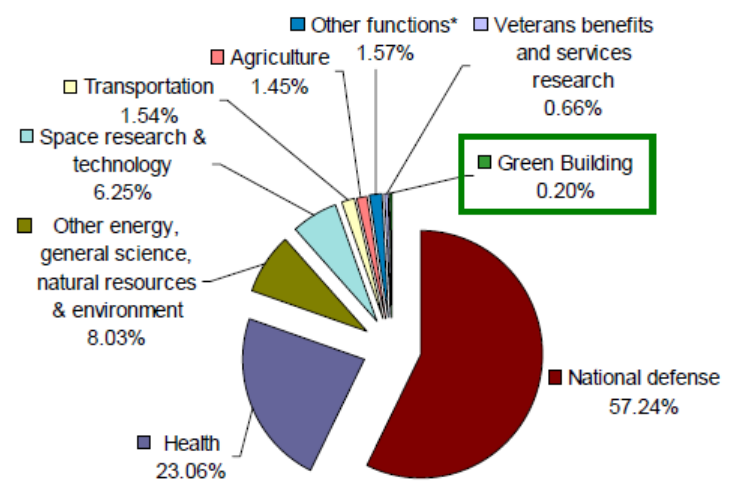

Fig. 3 Federal R\&D Budget Authority, by Budget Function FY2003-2005 
Other functions include education, training, employment, and social services, income security, and commerce. Green building data was compiled from agencies and the Office of Management and Budget (OMB), baseline federal R\&D budget data comes from the National Science Foundation (NSF). The $0.2 \%$ funding toward green buildings does not include money from the Department of Defense. Green buildings research already makes a difference, but a greater commitment to this research could make an even more profound difference. To do so, however, funding for green buildings research must be commensurate with that of other streams of research, and commensurate to the severity of the problems that buildings create, the current $0.2 \%$ of Federal research dollars will not be adequate to address these critical issues in a timely manner. However the built environment, including buildings and other development, plays a substantial role in the environmental health, human welfare and economic, the built environment, including roads, bridges and other civil structures.

Buildings also have a significant impact on human health. Most people spend an average of $90 \%$ of the day indoors. A significant number of all buildings are associated with sick building syndrome or building related illness, up to $30 \%$ new and remodeled buildings may experience acute indoor air quality problems. Indoor air typically contains between 2 and 5 -and at times greater than 100 - times more pollutants than outdoor air. As a result, poor indoor air quality in buildings has been linked to significant health problems such as cancers, asthma, Legionnaires' disease and hypersensitivity pneumonitis.

So building industries - including architecture, engineering, manufacturing, construction and other operations should be taken in the considerations of the designer to avoid the side effect of building pollutions,

American Society for Heating, Refrigerating and Air Conditioning Engineers (ASHRAE) of professional organizations involved with green building, ASHRAE funds the largest amount of research, about $65 \%$ of its budget goes to topics in energy and atmosphere, indoor environmental quality and related design tools. Within these areas, research projects are largely selected by ASHRAE's Technical Committees and are implemented by a competitive bid process, the following chart show the largest amount for research, about $65 \%$ of its budget goes for green building research, as shown in the diagram fig. 4

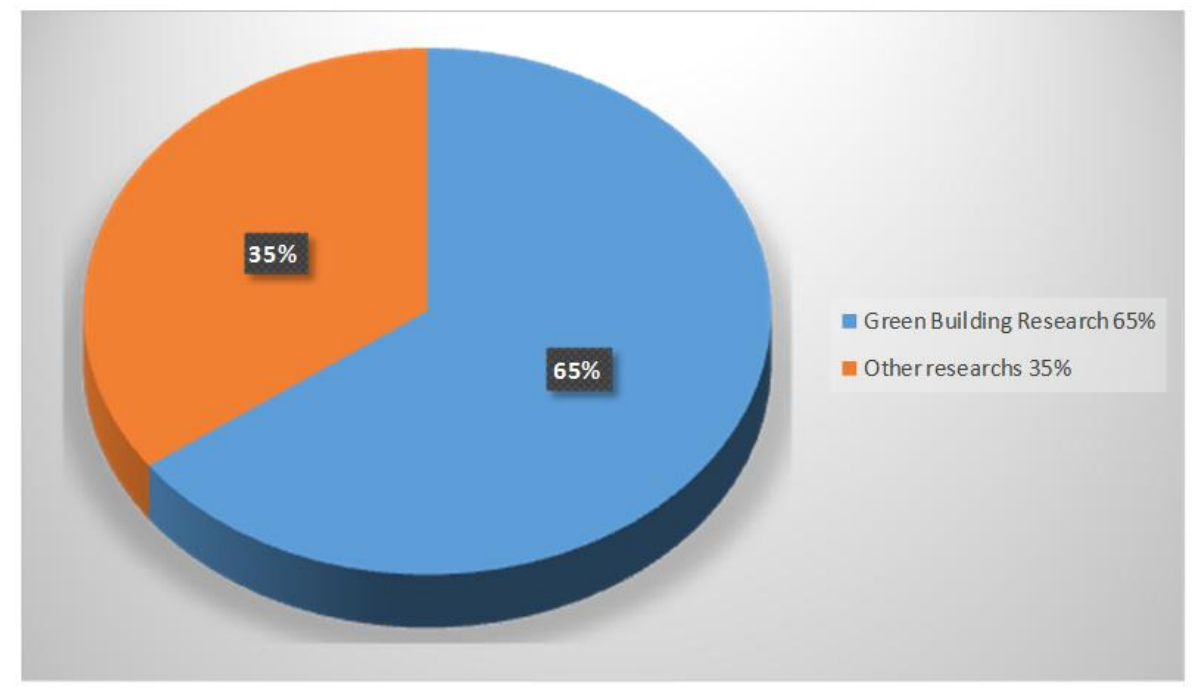

Fig. 4 The ratio of the budget which goes for green building research

\section{Objectives}

The main objective of this research is to achieve the standards of the global $\mathrm{CO}_{2}$ Emission, because the built environment has a vast impact on the natural environment. As well as raising awareness among the people through the curriculum in schools and universities, in addition to use different means of advertising and advertising that have an impact on the citizen, which confirms the advantages of this type of buildings as well as the government's contribution in spreading that awareness through their own government buildings, in order to encourage citizens to use such style of constructions, as well as the implementation of laws in this type of buildings, and do not forget the role of the Saudi Engineers Commission in its application of these laws and regulations, to be adopted in the local engineering offices. Green buildings evaluation criteria" and "green building technology guide", as well as national conditions for the scientific definition of green buildings. These initiatives will be important to maximize the conservation of resources (energy, land, water, material) through the building's life cycle, protect the environment, reduce pollution and provide a clean, enjoyable and useful space for people, where architecture coexist in harmony with nature. There is increasing importance for architects to design with emphasis on energy savings. Bad wind environment in the city hinders the flow of 
indoor and outdoor ventilation, increases air conditioning use in the summer, and leads to an increase of energy consumption for heating in the winter.

Modern technology used in analyzing the efficiency of buildings' design for good wind environment quality can effectively reduce the energy consumption of buildings. In the long-term, using natural ventilation provides a healthier, more low-cost method to provide clean air and other benefits to the users' physical health and psychological needs. This method also has a positive relationship with nature, and utilizes energy conservation, contributing to environmental protection. Like many environmental movements, the green building movement's roots can be traced back to the 1970's, when high oil prices and general awareness of environmental concerns spurred the earliest experiments in green building. It was not until the 1990's, however, that a true movement focused on green construction began to form. This corresponds with the vision and mission of the Saudi Green Building Council.

\section{Conclusion\& Recommendations}

Based on the special questionnaire were designed in order to get the views of the target group in this research, it was found that $65 \%$ of this group strongly supports this type of constructions being contributes to the preservation of human beings and the environment, and there are $20 \%$ of the research community does not quite know about this subject, so the engineering offices must take the initiative to communicate the extent of the benefit of the application of these systems, while we find that $15 \%$ of this segment do not want an increase in construction costs and meet the requirements of this system, since the cost of energy consumption is not expensive. As shown if fig. 5

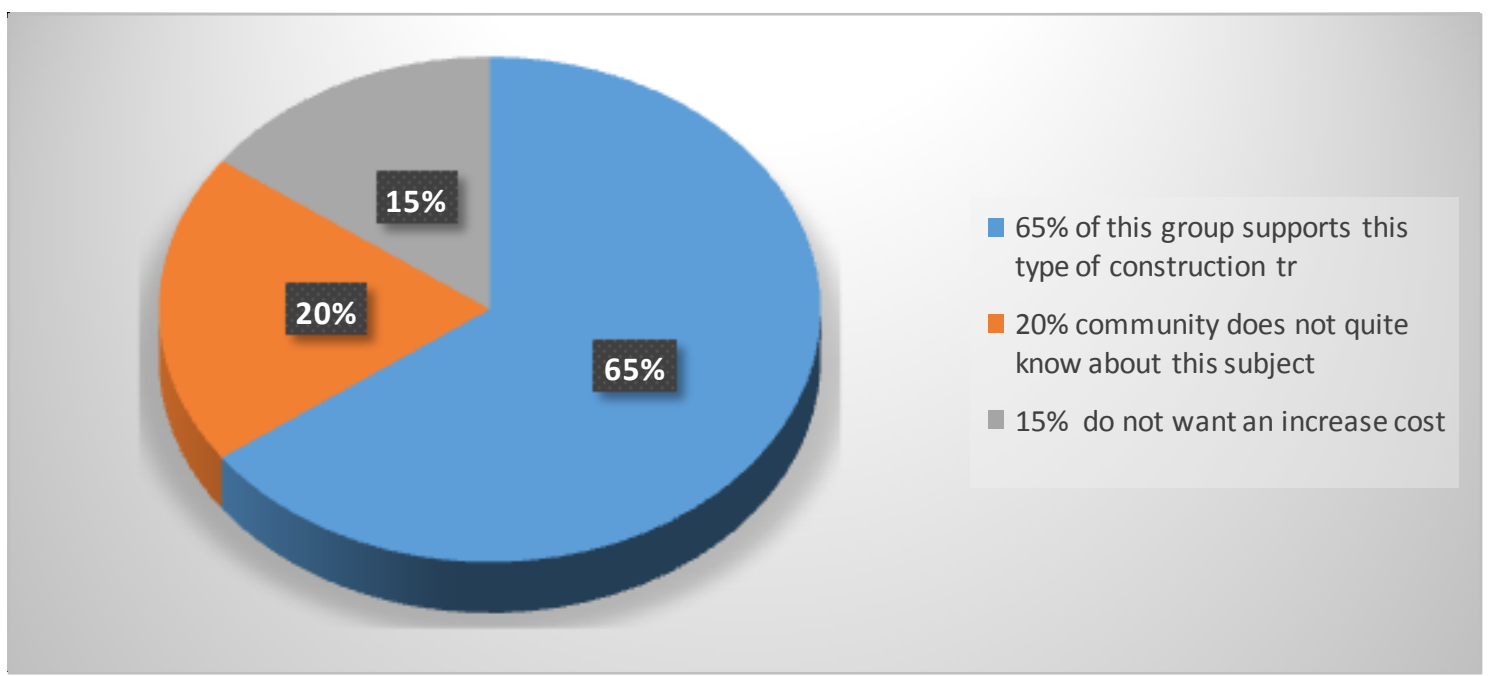

Fig. 5 show the statistical distribution for the search society

So the benefits of green construction with a focus on sustainable and efficient growth, the green building movement's benefits spread across environmental, economic, and social arenas. While satisfying the primary goal of achieving environmental benefits, so the majority of the citizen in the area of research is doing well about such issue, just implementation of the rules of green buildings by the engineering offices and confirm it from the authority body. It means that it's possible to apply such system soon.

\section{Acknowledgements}

First of all I would like to express my great thanks to God Almighty for helping me to finish this humbly research. It's my pleasure to express my special thanks to "Taif University Administration", for their full support to the scientific research in the university, I'm also grateful to my family, all engineers and engineering companies who gave me their hands to help, such as granting and supporting me by the data that I need to complete the research. Finally, I'm very much appreciate the encouragement and friendly assistance given to me from all colleagues. 


\section{References}

[1]. Francisco Gómez1; José Jabaloyes2; Luis Montero3; Vicente De Vicente4; and Manuel Valcuende5, Green Areas, the Most Significant Indicator of the Sustainability of Cities: Research on Their Utility for Urban Planning. JOURNAL OF URBAN PLANNING AND DEVELOPMENT @ ASCE / SEPTEMBER 2011 / 325.

[2]. Feng Qian and Li Yang, Natural Ventilation Environment Strategy in Green Building Design, Nature Environment and Pollution Technology An International Quarterly Scientific Journal, Vol. 15 No. 1 pp. 129-134 2016.

[3]. E ERIC BOSCHMANN AND JESSICA N GABRIEL, Urban sustainability and the LEED rating system: case studies on the role of regional characteristics and adaptive reuse in green building in Denver and Boulder, Colorado.

[4]. Levett, R. 1998. Sustainability indicators - integrating quality of life and environmental protection. Journal of the Royal Statistical Society A, 161(3): 406-410.

[5]. JESSICA ALFANO, CAN WE (ANTI)TRUST LEED?: N ANALYSIS OF THE ANTITRUST IMPLICATIONS FOR THE GREEN BUILDING MOVEMENT, BOSTON COLLEGE ENVIRONMENTAL AFFAIRS LAW REVIEW, 2013 - 2014.

[6]. Kevin R. Anderson, Ian Villazana, Thomas Gross, Case study of building energy load calculations for a sustainable technology demonstration project. INTERNATIONAL JOURNAL OF ENERGY AND ENVIRONMENT, Volume 7, Issue 4, 2016 pp.283290. www.IJEE.IEEFoundation.org. http://gbc-saudi.org/?page_id=93\&lang=ar.

[7]. ASCE/UNESCO. 1998. Sustainability criteria for water resource systems. American Society of Civil Engineers (ASCE), Task Committee on Sustainability Criteria and Working Group of UNESCO/IHP-IV Project M-4.3. American Society of Civil Engineers,

[8]. Foxon, T.J., Leach, M., Butler, D., Dawes, J., Hutchinson, D., Pearson, P., and Rose, D. 1999. Useful indicators of urban sustainability: some methodological issues. Local Environment, 4(2): 137-149. Reston, Va.

[9]. A. Gandhimathi and D. Suji, Studies on the Development of Eco-friendly Self-healing Concrete - A Green Building Concept, Nature Environment and Pollution Technology An International Quarterly Scientific Journal, Vol. 14 No. 3 pp. $639-6442015$.

[10]. Jiang Qifa, Economic Analysis on Chinese Green Buildings in the Context of Life Cycle Costing, 6th International Conference on Information Management, Innovation Management and Industrial Engineering 2013.

[11]. Cheng-Li Cheng, Jr-Jie Peng 1, Ming-Chin Ho 2, Wan-Ju Liao 3 and Szu-Jen Chern 1, Evaluation of Water Efficiency in Green Building in Taiwan, Ling TimWong, 1 June 2016.

[12]. Goh Bee Hua, BIM Based Application to Support Cost Feasible 'Green Building' Concept Decisions, National University of Singapore, Singapore, Copyright @ 2010.

[13]. Seeley, I. H. Building Economics: Appraisal and Control of Building Design Cost and Efficiency. London: Macmillan. 1981.

[14]. Martin Riese, Building Lifecycle Information Management Case Studies, DOI: 10.4018/978-1-60566-928-1.ch028, Copyright (C) 2010, IGI Global.

[15]. Wen-Hsien Tsaia, Sin-Jin Linb, Ya-Fen Leea, Yao-Chung Changa and ui-Ling Hsu, Construction method selection for green building projects to improve environmental sustainability by using an MCDM approach, Journal of Environmental Planning and Management, Vol. 56, No. 10, 1487 - 1510. 2013. 